\title{
Effective methods of parameter identification for creep models with account of III stage
}

\author{
Alexey I. Grishchenko, a and Artem S. Semenov ${ }^{1}$ \\ ${ }^{1}$ St.Petersburg State Polytechnical University, Polytechnicheskaya st.29,195251, Saint-Petersburg, Russia
}

\begin{abstract}
The account of tertiary (third) stage of creep is important for the failure analysis of structures. The correct description of third stage of creep is based on taking into account of damage accumulation process. An identification of the parameters of coupled creep-damage model leads to the optimization problem of finding the global minimum of a functional, having a complex, non-linear structure and a large number of local minimums. The Nelder-Mead method is applied to the solution to the multiparameter identification problem. The effectiveness and robustness of the applied approach are illustrated on examples of mechanical and civil engineering.
\end{abstract}

\section{Introduction}

The creep process is described by the so-called creep curve, which represents the time dependence of the strain at constant temperature and applied load (or stress). It is conventionally divided into three sections or stages (Fig. 1): initial stage, or primary creep, when the strain rate slows with increasing time, secondary or steady state of creep, when the strain rate eventually reaches a minimum and becomes near constant and in tertiary creep, the strain rate exponentially increases with stress. Fracture always occurs at the tertiary stage.

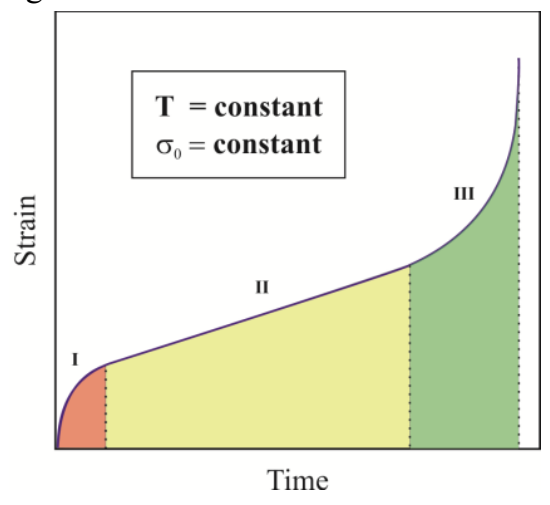

Figure 1. Schematic representation of creep curve showing primary (I), secondary (II) and tertiary (III) deformation regimes.

Corresponding author: gai-gr@yandex.ru

This is an Open Access article distributed under the terms of the Creative Commons Attribution License 4.0, which permits unrestricted use, distribution, and reproduction in any medium, provided the original work is properly cited. 
For most materials, the main time before the failure takes the second stage of the creep. Therefore, to describe the creep curves of these materials is sufficient to use the model, taking into account only the second (steady state) stage of the creep. However, some materials, such as single crystal nickel base superalloys [1,2], heat-resistant steel [3,4] or asphalt mastic [5], demonstrate domination of the third stage of creep. To describe the creep of such materials, it is necessary to use models that describe correctly a third stage of creep. The correct description of third stage of creep is based on taking into account of damage accumulation process.

\section{Materials and Methods}

\subsection{Constitutive equations of creep}

In this work the Kachanov-Rabotnov model [3] is used for description a third stage of creep:

$$
\begin{gathered}
\frac{d \varepsilon^{c}}{d t}=B \frac{\sigma^{n}}{(1-D)^{l}}\left(\varepsilon^{c}\right)^{m}, \\
\frac{d D}{d t}=K \frac{\sigma^{p}}{(1-D)^{q}},
\end{gathered}
$$

where $\mathrm{D}$, is scalar damage variable $(0 \leq D \leq 1)$.

After integration (1), (2) obtain:

$$
\varepsilon^{c}=\left\{\frac{1-m}{1-\frac{l}{1+q}} \frac{B}{K(q+1)} \sigma^{n-p}\left[1-\left(1-K(q+1) \sigma^{p} t\right)^{1-\frac{l}{q+1}}\right]\right\}^{\frac{1}{1-m}} .
$$

Thus, it is generally necessary to determine the seven constants: $B, n, K, q, l, p, m$.

Checking of the correctness of determining the coefficients $K$ and $p$ equation (2) may be carried out by means of conditions for the destruction $D\left(t=t_{f}\right)=1$, where $D$ is found by integrating (2) with zero initial conditions $(D(t=0)=0)$ and constant stress. The result of the integration of $(2)$ may be expressed as follows:

$$
D=1-\left(1-t / t_{f}\right)^{1 / q+1},
$$

where $t_{f}$ is time before the failure

$$
t_{f}=\frac{1}{(q+1) K \sigma^{p}} .
$$

Taking into account equation (4) and (5) the equation (3) can be rewritten as: 


$$
\varepsilon^{c}=\left\{\frac{1-m}{1-\frac{l}{1+q}} B \sigma^{n} t_{f}\left[1-\left(1-\frac{t}{t_{f}}\right)^{1-\frac{l}{q+1}}\right]\right\}^{\frac{1}{1-m}} .
$$

In this paper $n=l$ is used.

For simplification the definition of material parameters (6) can be rewritten as:

where

$$
\varepsilon^{c}=\left\{A \sigma^{x}\left[1-\left(1-K_{1} \sigma^{p} t\right)^{v}\right]\right\}^{m_{1}}
$$

$$
A=\frac{1-m}{1-\frac{l}{1+q}} \frac{B}{K(q+1)} ; x=l-p ; K_{1}=K(1+q) ; v=1-\frac{l}{q+1} ; m_{1}=\frac{1}{1-m},
$$

Units of measurement are

follows: $[A]=\frac{1}{[M P a]^{x}} ;\left[K_{1}\right]=\frac{1}{s \cdot[M P a]^{p}} ;[x]=[l]=[v]=\left[m_{1}\right]=[1]$.

Defining the parameters of the material was carried out by means of minimization of the objective function:

$$
L=\sum_{i=1}^{n} \sum_{j=1}^{k}\left[\left\{A \sigma_{i}^{x}\left[1-\left(1-K_{1} \sigma_{i}^{p} t_{j}\right)^{v}\right]\right\}^{m_{1}}-\varepsilon\left(\sigma_{i}, t_{j}\right)\right]^{2} \rightarrow \min
$$

This functional has a complex, non-linear structure and a large number of local extremums. The solution to this problem is not trivial. When we using the Newton's method, the Gradient descent method we have not received the result. In this works for solution of this problem was use NelderMead method.

\subsection{Nelder-Mead method}

The Nelder-Mead method is a numerical method used to find the minimum or maximum of an objective function in a many-dimensional space. It is applied to nonlinear optimization problems for which derivatives may not be known. This method is described in detail in literature [6,7], and we are shown only principal scheme of this method.

1. Initially selected $\mathrm{n}+1$ point $x_{i}^{(k)}=x_{i}\left(x_{i_{1}}^{(k)}, x_{i_{2}}^{(k)}, \ldots \ldots, x_{i_{n}}^{(k)}\right), i=1, n+1$, where $k$ is iteration number.

2. Ordering. Determine three points:

$$
\begin{aligned}
& x_{h}^{(k)}: f\left(x_{h}^{(k)}\right)>f\left(x_{i}^{(k)}\right), i=1, n ; x_{l}^{(k)}: f\left(x_{h}^{(k)}\right)<f\left(x_{i}^{(k)}\right), i=1, n ; \\
& x_{g}^{(k)}: f\left(x_{h}^{(k)}\right)>f\left(x_{i}^{(k)}\right), i=1, n, i \neq h
\end{aligned}
$$

3. Calculate the mass center $x_{0}^{(k)}$ of all points. $x_{0}^{(k)}=\sum_{i=1}^{n+1} x_{i}^{(k)}-x_{n}^{(k)} / n$

4. Transformation. Compute the new working simplex from the current one. 
5. Reflect. Compute reflected point $x_{r}^{(k)}=x_{0}^{(k)}+\alpha\left(x_{0}^{(k)}-x_{n+1}^{(k)}\right)$. If, $f\left(x_{l}^{(k)}\right) \leq f\left(x_{r}^{(k)}\right)<f\left(x_{g}^{(k)}\right)$ accept $x_{r}^{(k)}$ and go to 7 .

6. Expand. If $f\left(x_{r}^{(k)}\right)<f\left(x_{l}^{(k)}\right)$ compute the expansion point $x_{e}^{(k)}=x_{0}^{(k)}+\gamma\left(x_{0}^{(k)}-x_{n+1}^{(k)}\right)$. If $f\left(x_{e}^{(k)}\right)<f\left(x_{r}^{(k)}\right)$, accept $x_{e}^{(k)}$ and go to 7. Else, if $f\left(x_{e}^{(k)}\right) \geq f\left(x_{r}^{(k)}\right)$, accept $x_{r}^{(k)}$ and go to 7 .

7. Contact. It is certain that $f\left(x_{r}^{(k)}\right) \geq f\left(x_{g}^{(k)}\right)$, compute the contraction point:

8. If $\left(x_{g}^{(k)}\right) \leq f\left(x_{r}^{(k)}\right)<f\left(x_{h}^{(k)}\right)$, compute $x_{c}^{(k)}: x_{c}^{(k)}=x_{0}^{(k)}+\rho\left(x_{r}^{(k)}-x_{0}^{(k)}\right)$. If $f\left(x_{c}^{(k)}\right)<f\left(x_{r}^{(k)}\right)$, accept $x_{c}^{(k)}$ and go to 7 .

9. If $\left(x_{r}^{(k)}\right) \geq f\left(x_{h}^{(k)}\right)$, compute $x_{c}^{(k)}: x_{c}^{(k)}=x_{0}^{(k)}+\rho\left(x_{h}^{(k)}-x_{0}^{(k)}\right)$. If $f\left(x_{c}^{(k)}\right)<f\left(x_{h}^{(k)}\right)$, accept $x_{c}^{(k)}$ and go to 7 .

10. For all but the best point, replace the point with $x_{i}^{(k)}=x_{1}^{(k)}+\mu\left(x_{0}^{(k)}-x_{1}^{(k)}\right), i=2, n+1$. Go to step 7.

11. End the search criterion: $\left\{\frac{1}{n+1} \sum_{i=1}^{n+1}\left[f\left(x_{i}^{(k)}\right)-f\left(x_{0}^{(k)}\right)\right]^{2}\right\} \leq_{\varepsilon}$, where $\varepsilon$ is the arbitrary small number, $f\left(x_{0}^{(k)}\right)$ - is the value of the objective function at the center of mass of all points.

\section{Results and Discussion}

\subsection{Result of parameter identification for creep models of single crystal nickel base superalloys}

The constants of the creep model (1)-(2) for single crystal alloys VZhM4 and VZhM5Y with crystallographic orientation $<001>$ at $1050{ }^{\circ} \mathrm{C}$ were determined. Experimental creep curves were obtained in the laboratory of Strength of materials [8-10]. Creep curves for the following stress: 250, 280 and $320 \mathrm{MPa}$ were investigated. The experimental creep curves and their approximation by (7) are shown in Fig. 2. Mean square deviation between the experimental points and approximation was $1 \%$. The creep model parameters for single crystal alloys VZhM4 and VZh5MY are given in Tab. 1.

Table 1. The creep model parameters for single crystal alloy VZhM4 and VZhM5Y

\begin{tabular}{|l|c|c|c|c|c|c|}
\hline & $A$ & $x$ & $K_{1}$ & $p$ & $v$ & $m$ \\
\hline VZhM4 & 2010 & $1,0 \cdot 10^{-6}$ & $1,58 \cdot 10^{-13}$ & 5,63 & $9,6 \cdot 10^{-4}$ & 1,83 \\
\hline VZhM5Y & 929 & $5,0 \cdot 10^{-5}$ & $1,12 \cdot 10^{-12}$ & 5,01 & $2,66 \cdot 10^{-3}$ & 1,51 \\
\hline
\end{tabular}



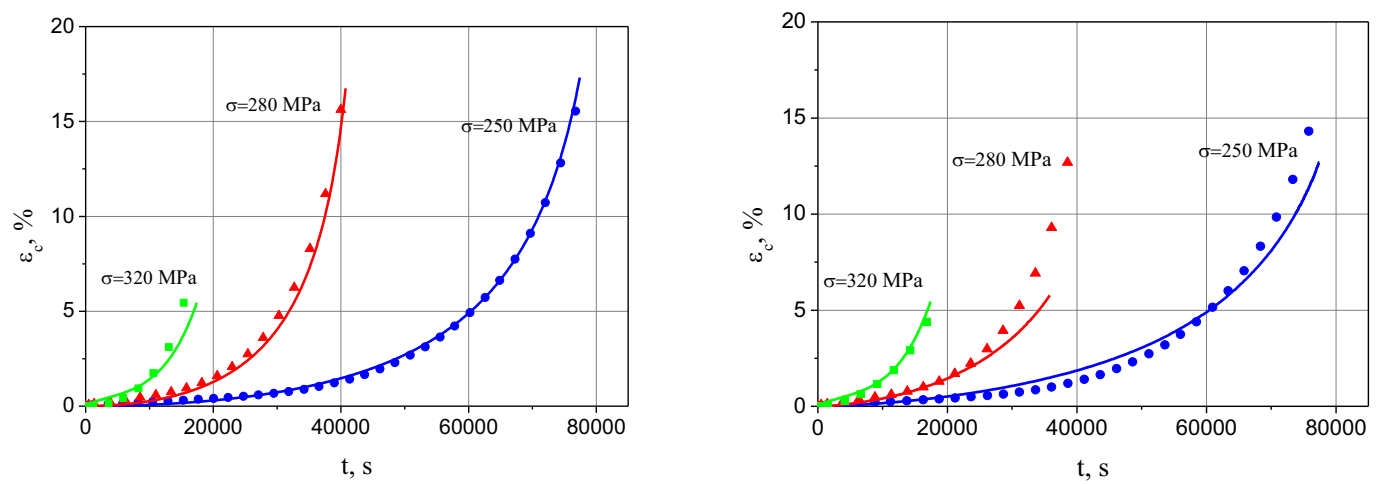

Figure 1. Experimental creep curves (points) [8-10] and their approximation with using creep model (solid lines) for single crystal nickel base superalloys VZhM4 (a) and VZhM5Y (b).

\subsection{Result of parameter identification for creep models of heat-resistant steel}

The constants of the creep model (1)-(2) for Type $304 \mathrm{H}$ austenitic stainless steel at $650^{\circ} \mathrm{C}$ are determined. We use experimental creep curves from [4]. Creep curves for the 250, 280 and $320 \mathrm{MPa}$ are considered. The experimental creep curves and their approximation by (7) are shown in Fig. 2. Mean square deviation between the experimental points and approximation was $0.4 \%$. The creep model parameters for Type304H austenitic stainless steel were shown in Tab. 2.

Table 2. The creep model parameters for Type304H austenitic stainless steel

\begin{tabular}{|c|c|c|c|c|c|c|}
\hline & $A$ & $x$ & $K_{l}$ & $p$ & $v$ & $m$ \\
\hline HR steel & $2,31 \cdot 10^{-7}$ & 3,01 & $1,63 \cdot 10^{-15}$ & 6,91 & $3,09 \cdot 10^{-7}$ & 1 \\
\hline
\end{tabular}

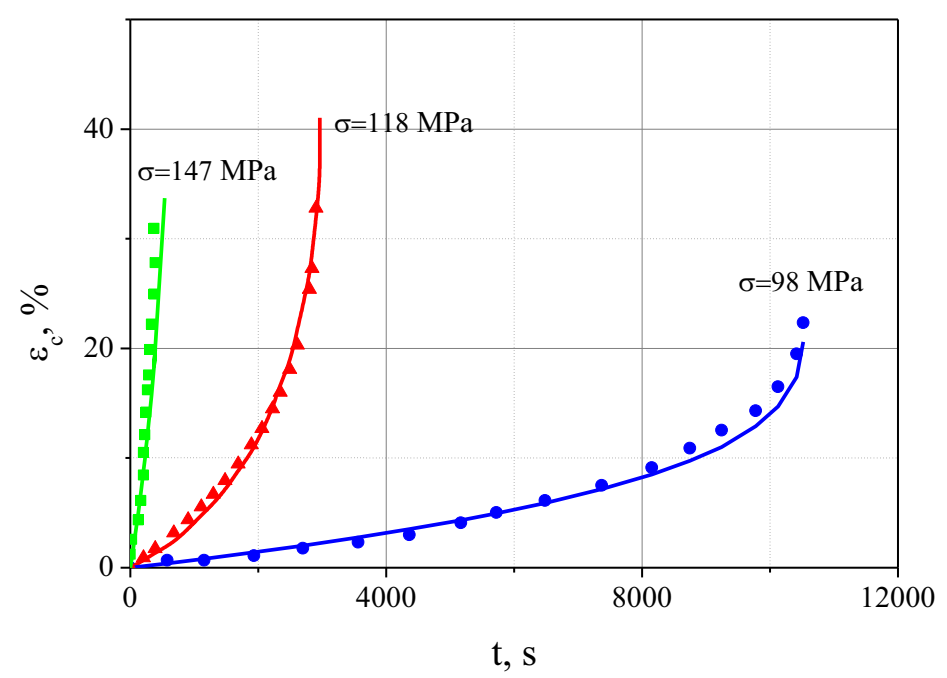

Figure 2. Experimental creep curves and their approximation with using creep model (1)-(2) for Type304H austenitic stainless steel at $650^{\circ} \mathrm{C}$. The lines show the approximation of creep curves, points shows the experimental data [4]. 


\subsection{Result of parameter identification for creep models of asphalt mastic}

The constants of creep model for asphalt mastic at $40^{\circ} \mathrm{C}$ were determined. We use experimental creep curves from [5]. Creep curves for the following stress: $0.1,0.15,0.2,0.25$ and $0.3 \mathrm{MPa}$ was investigated. The experimental creep curves and their approximation by (7) are shown in Fig. 3. Mean square deviation between the experimental points and approximation was $2 \%$. The creep model parameters for asphalt mastic was shown in table 3.

Table 3. The creep model parameters for asphalt mastic

\begin{tabular}{|c|c|c|c|c|c|c|}
\hline & $A$ & $x$ & $K_{I}$ & $p$ & $v$ & $m$ \\
\hline Asphalt mastic & 46,6 & 1,33 & $2,61 \cdot 10^{-2}$ & 2,19 & $2,21 \cdot 10^{-5}$ & 0,49 \\
\hline
\end{tabular}

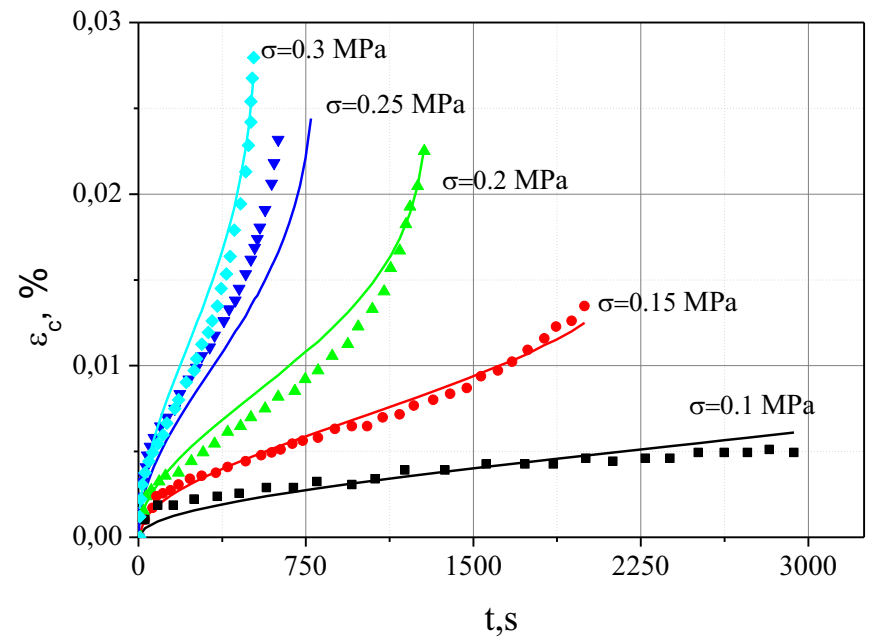

Figure 3. Experimental creep curves and their approximation with using creep model (1)-(2) for asphalt mastic. The lines show the approximation of creep curves, points show the experimental data [5].

\section{Conclusions}

The modeling of creep process has been analyzed for three different class of materials:

- $\quad$ single-crystal nickel-based alloys VZhM4 and VZhM5Y,

- $304 \mathrm{H}$ austenitic stainless steel,

- asphalt mastic.

The obtained results of creep analysis allow to find out:

- the creep model in the form of the hardening theory considering damage accumulation is applicable for creep behavior prediction with account of III stage for all considered materials,

\section{Acknowledgments}

This research was supported by the Russian Foundation for Basic Research (Grant No. 15-08-08779). The authors are grateful to O.A. Fedorov for help in writing program of creep curves approximation. 


\section{References}

1. R.E. Shalin, I.L.Svetlov, E.B. Kachanov, Mechanical Engineering, Moscow, (1997)

2. R.C. Reed, Cambridge University Press, (2006)

3. S.R. Holdsworth, Woodhead Publishing; CRC Press, pp 403-420, (2008)

4. M. Igarashi, Woodhead Publishing; CRC Press, 539-596 (2008)

5. Y. Ye, X. Yang, C. Chen, Construction and Building Materials, 23, 3161-3165 (2009)

6. J.A. Nelder, R. Mead, Comput. J., 7, 308-313 (1965)

7. D.M. Himmelblau, McGraw-Hill, New York (1972)

8. L.B. Getsov, A.S. Semenov, E.A. Tikhomirova, A.I. Rybnikov, Materiali in Tehnologije, 48(2), 255-260 (2014)

9. S.G. Semenov, L.B. Getsov, E.A. Tikhomirova, A.S. Semenov, Metal Science and Heat Treatment, 2016 (to be published)

10. S.G. Semenov, L.B. Getsov, A.S. Semenov, N.V. Petrushin, O.G. Ospennikova, A.A. Zhivushkin, Problems of mechanical engineering and reliability of the machines, 2, 2016 (to be published). 